\title{
Acknowledgements
}

This book has a long history, dating back to 1986 when I wrote a dissertation on Troy Kennedy Martin for an MA in Film Studies at the Polytechnic of Central London. My first thanks, therefore, go to my MA tutor, Richard Collins, who planted the seed of an idea that, twenty years later, has grown into this book. Along the way many other people have contributed, in a variety of ways, to the end product. I am very grateful to Peter Duguid, Tony Garnett, Ian Kennedy Martin, the late John McGrath, David Rose, Roger Smith and Michael Wearing for giving me some of their time to talk about working with Troy. I would also like to acknowledge the help of Kathleen Dickson and Janet Moat at the British Film Institute, Trish Hayes at the BBC Written Archives Centre, Christine Slattery at the BBC TV Archive, and Veronica Taylor at the National Film Theatre.

While writing this book I was in receipt of a grant from the Arts and Humanities Research Board (now Centre), primarily to finance the completion of a Ph.D. at Manchester Metropolitan University (MMU) as part of the threeyear research project, Cultures in British Television Drama, 1960-82. I am grateful to the project supervisors, Jonathan Bignell and Stephen Lacey, and to Robin Nelson at MMU, for tolerating the amount of time I spent on this book while I was also working on the Ph.D. (and writing a few other things besides!). Sincere thanks go to the series editors, Jonathan Bignell and Sarah Cardwell, and to Matthew Frost and Jonathan Bevan (and before him Kate Fox) at Manchester University Press for their patience as I tried to juggle my different research and writing commitments.

Thanks are also due to a number of other people who have contributed in ways great or small to this book: Caroline Aperguis, Nevena Dakovic, Mark Duguid, Dick Fiddy, Stephen Griffiths, Peter Hames, Elizabeth MacLennan, John Manuel, Nicky North and Jo Wright. Thanks should also go to all the students, over a period of twenty years, with whom I have shared thoughts and ideas about the work of Troy Kennedy Martin.

My most sincere thanks go to Troy Kennedy Martin himself, without whose help this book would not be as complete as it is. Over a period of some years now he has been extremely generous with his time, allowing me to quiz him for hours about his work and providing access to many scripts and notes from his 


\section{viii Acknowledgements}

personal collection. While he may not agree with everything I have written, his assistance along the way has been invaluable. 